\title{
Osteopontin is required for mechanical stress-dependent signals to bone marrow cells
}

\author{
Muneaki Ishijima, Kunikazu Tsuji, Susan R Rittling ${ }^{1}$, Teruhito Yamashita, Hisashi Kurosawa ${ }^{2}$, \\ David T Denhardt ${ }^{1}$, Akira Nifuji, Yoichi Ezura and Masaki Noda \\ Department of Molecular Pharmacology, Medical Research Institute, Tokyo Medical and Dental University, 3-10, Kanda-Surugadai 2-Chome, Chiyoda-Ku, \\ Tokyo 101-0062, Japan \\ ${ }^{1}$ Department of Cell Biology and Neuroscience, Rutgers University, Piscataway, New Jersey 08854-8082, USA \\ ${ }^{2}$ Department of Orthopaedics, School of Medicine, Juntendo University, Tokyo 113-8421, Japan \\ (Requests for offprints should be addressed to M Noda; Email: noda.mph@mri.tmd.ac.jp and KTsuji; Email: kunikazut3@hotmail.com)
}

\begin{abstract}
Mechanical stress to bone plays a crucial role in the maintenance of bone homeostasis. It causes the deformation of bone matrix and generates strain force, which could initiate the mechanotransduction pathway. The presence of osteopontin (OPN), which is one of the abundant proteins in bone matrix, is required for the effects of mechanical stress on bone, as we have reported that OPN-null $(\mathrm{OPN}-/-)$ mice showed resistance to unloading-induced bone loss. However, cellular mechanisms underlying the phenomenon have not been completely elucidated. To obtain further insight into the role of OPN in mediating mechanical stress effect on bone, we examined in vitro mineralization and osteoclast-like cell formation in bone marrow cells obtained from hind limb bones of OPN - / mice after tail suspension. The levels of mineralized nodule formation of bone marrow cells derived from the femora subjected to unloading were decreased compared with that from loaded control in wild-type mice. However, these were not

decreased in cells from $\mathrm{OPN}-/-$ mice after tail suspension compared with that from loaded OPN $-/-$ mice. Moreover, while spreading of osteoclast-like cells derived from bone marrow cells of the femora subjected to unloading was enhanced compared with that from loaded control in wild-type mice, this enhancement of spreading of these cells derived from the femora subjected to unloading was not recognized compared with those from loaded control in OPN $-/-$ mice. These data provided cellular bases for the effect of the OPN deficiency on in vitro reduced mineralized nodule formation by osteoblasts and on enhancement of osteoclast spreading in vitro induced by the absence of mechanical stress. These in vitro results correlate well with the resistance to unloading-induced bone loss in $\mathrm{OPN}-/-$ mice in vivo, suggesting that $\mathrm{OPN}$ has an important role in the effects of unloading-induced alterations of differentiation of bone marrow into osteoblasts and osteoclasts. Journal of Endocrinology (2007) 193, 235-243
\end{abstract}

\section{Introduction}

Mechanical stimuli are known to be one of the crucial factors maintaining bone mass (Lian et al. 1996, Ducy et al. 2000, Manolagas 2000). For instance, while high impact sports and, moreover, very low magnitude, high frequency vibration could increase bone mass, prolonged bed rest and extended spaceflight leads to bone loss (Morey \& Baylink 1978, Bikle \& Halloran 1999, Rubin et al. 2001b). Mechanical stimuli loaded to bone have been thought to cause the deformation of bone matrix and generate strain force, which initiates the mechanotransduction pathway (Burger \& Klein-Nulend 1999, Nomura \& Takano-Yamamoto 2000). Each cell is attached to its surrounding matrix through membrane receptors called integrin for extracellular matrix protein (Rodan 1991, Ingber 1999). These transmembrane receptors could provide a direct link between the extracellular matrix and cytoskeleton and could mediate changes in matrix strain (Wang et al. 1993, Shyy \& Chien 1997, Wozniak et al. 2000). However, molecular mechanisms involved in these phenomena are not yet fully understood.

Osteopontin (OPN) is a phosphorylated acidic glycoprotein present in extracellular matrix of mineralized tissues and is one of the abundant non-collagenous proteins in bone matrix produced by osteoblasts, osteoclasts, and probably osteocytes (Rodan 1991, Butler et al. 1996, Denhardt \& Noda 1998). This protein contains an arginine-glycineaspartate sequence that is a major integrin-binding site and supports adhesion of bone cells to the mineralized matrix (Giachelli \& Steitz 2000, Denhardt et al. 2001b). It has been reported that OPN is required for stress-induced bone remodeling, such as ovariectomy or ectopic bone disc implantation (Rittling \& Denhardt 1999, Yoshitake et al. 1999, Asou et al. 2001, Ihara et al. 2001, Nemoto et al. 2001, Kitahara et al. 2003). 
OPN has also been reported to be regulated by mechanical stress both in vitro and in vivo (Kubota et al. 1993, Harter et al. 1995, Klein-Nulend et al. 1997, Toma et al. 1997, Carvalho et al. 1998, Meazzini et al. 1998, Miles et al. 1998, Terai et al. 1999, Denhardt et al. 2001a, You et al. 2001, Morinobu et al. 2003). These observations could be related to the reciprocally coordinated regulation of OPN in bone remodeling. Recently, we reported that OPN is necessary for unloadinginduced enhancement of bone resorption and suppression of bone formation in vivo (Ishijima et al. 2001, 2002). These data suggest that OPN plays a key role in conveying the effect of mechanical stress to osteoclasts and osteoblasts. However, molecular mechanisms of OPN function in mechanotransduction pathways are not completely elucidated.

Bone marrow stromal cells are known to play an integral part in bone formation by providing an osteoprogenitor cell source capable of differentiating into mature osteoblasts in response to mechanical stresses (Mauney et al. 2004, Koike et al. 2005). On the other hand, the osteopenic response to reduced mechanical stress has been known to be well associated with the decrease in the number of osteoprogenitor cells, proliferation and differentiation in bone marrow cells (Bikle et al. 1994, Keila et al. 1994, Barou et al. 1998, Kostenuik et al. 1999, Sakata et al. 1999, Sakai et al. 2002). These data indicate that mechanical stress, whenever it is applied or reduced, could affect the characteristics of not only osteoblasts and osteoclasts but also bone marrow cells. In addition, OPN is considered to be involved in these processes (Ishijima et al. 2001, 2002, Mauney et al. 2004).

Thus, in this study, we examined characteristics of bone marrow cells in the femora in $\mathrm{OPN}-/-$ mice after tail suspension using mineralized nodule formation and osteoclast-like cell formation assay to elucidate the role of OPN in osteoblastic and osteoclastic differentiation of bone marrow cells regulated by mechanical stress.

\section{Materials and Methods}

\section{Animals}

Female wild-type and OPN $-/-$ mice in a $129 / \mathrm{SV} \times$ C57BL/6 F2 background (Rittling et al. 1998) derived from the original heterozygous crosses were maintained as separate colonies. These mice were kept under controlled conditions at $24{ }^{\circ} \mathrm{C}$ with a ratio of $12 \mathrm{~h}$ light: $12 \mathrm{~h}$ darkness cycle with the light cycle starting at $0700 \mathrm{~h}$, fed with standard laboratory chow (MF; Oriental Yeast, Tokyo, Japan) and given tap water. Twelve-week-old female OPN - / - and wild-type mice (24 mice in total) were used in the experiments and randomly assigned in equal numbers to loaded control and tail suspension groups. All experiments were conducted according to the institutional guidelines for animal welfare.

\section{Tail suspension model}

The mice were subjected to tail suspension as described previously (Ishijima et al. 2001). Briefly, a tape was applied to the surface of the tail to set a metal clip. The end of the clip was fixed to the overhead bar and the height of the bar was adjusted to maintain an approximately $30^{\circ}$ head-down tilt with the hind limbs elevated above the floor of the cage. Mice were permitted to move within the cage using their forelimbs while their hind limbs were kept free of weight bearing. Onehalf of the mice in the tail suspension group was subjected to tail suspension for 7 days ( $n=6$ per group). Loaded control mice were also housed individually under the same conditions without tail suspension for the same duration (7 days). After tail suspension, mice were anesthetized with pentobarbital and were killed by cervical dislocation. The femora and tibiae were separated from adherent muscles and connective tissues other than periosteum. The tibiae were fixed with $70 \%$ ethyl alcohol solution for subsequent analysis of bone and the femora were used for the experiments to evaluate bone marrow cells as described below. All experiments in this study were conducted twice ( $n=3$ per group) and all data ( $n=6$ per group) were evaluated.

\section{Body weight of the animals}

To monitor the effects of tail suspension on the general condition of these animals, body weight of the mice in first experiment ( $n=3$ per each group, 12 in total) was measured every day during the experimental periods. Body weights of either loaded or tail suspended mice were not altered during experiments in both genotypes (data not shown). This confirms that stress can be considered minimal in our experiments, as previously concluded (Bikle et al. 1985). It is reported that extremely low-level stimulus may provide an effective biomechanical intervention for the bone loss (Rubin et al. 2001a). Therefore, when the mice were weighed, the tail-suspended mice were permitted to stand on all four legs for periods of no longer than $10 \mathrm{~s}$. Body weight of the mice in second experiment ( $n=3$ per each group, 12 in total) was not measured. As these two independent experiments showed similar results, we considered that the effect of mechanical stimulus by body weighing is minimal.

\section{Micro-X-ray computed tomography $(\mu-C T)$ analysis of bone}

For measurements of the bone volume/tissue volume (BV/TV), the bones were subjected to $\mu-\mathrm{CT}$ analysis, using Musashi (Nittetsu-ELEX, Tokyo, Japan). The data were subsequently quantified using a Luzex-F automated image analysis system (NIRECO, Tokyo, Japan). The fractional $\mathrm{BV} / \mathrm{TV}$ was measured in the area of $0.39 \mathrm{~mm}^{2}$ with its closest and furthest edges at 0.34 and $0.62 \mathrm{~mm}$ distal to the growth plate of the proximal ends of the tibiae. 


\section{Bone marrow cell cultures}

After 7 days of tail suspension, bone marrow cells were obtained from the right femora of either loaded or unloaded mice. The bone marrow was flushed from the bones. A single cell suspension was prepared by gentle pipetting and the number of total bone marrow cells was counted using a hematocytometer. The cells were plated into a $9 \cdot 6 \mathrm{~cm}^{2}$ culture well at a concentration of $5 \cdot 0 \times 10^{3}$ cells $/ \mathrm{cm}^{2}$ and cultured in 5\% $\mathrm{CO}_{2}$ and $95 \%$ air in a humidified atmosphere.

\section{Formation of mineralized nodule}

Bone marrow cells were cultured in six-well plates in Minimum Essential Medium alpha modification (Sigma) supplemented with $10 \%$ fetal bovine serum (Life Technologies), $1 \times$ antibiotic-antimycotic (Life Technologies), $2.2 \mathrm{mg} / \mathrm{ml}$ sodium bicarbonate (WAKO, Osaka, Japan), $50 \mu \mathrm{g} / \mathrm{ml}$ ascorbic acid (Sigma) and $10 \mathrm{mM}$ $\beta$-glycerophosphate (Sigma). The medium was changed every 3 days in culture. On the 21st day in culture, the cells were fixed with ethyl alcohol for $10 \mathrm{~min}$, stained with a saturated solution of Alizarin Red S (Sigma) for $15 \mathrm{~min}$, and washed with water. After drying the samples in the air, the dish surface area covered with dark stain representing mineralized nodules was measured using a Luzex-F automated image analysis system (NIRECO).

\section{Osteoclast-like tartrate-resistant acid phosphatase (TRAP)- positive multinucleated cell development}

Bone marrow cells were cultured in Minimum Essential Medium alpha modification supplemented with $10 \%$ fetal bovine serum, $1 \times$ antibiotic-antimycotic, $2 \cdot 2 \mathrm{mg} / \mathrm{ml}$ sodium bicarbonate, $10 \mathrm{ng} / \mathrm{ml}$ macrophage colony-stimulation factor (M-CSF; R\&D Systems, Minneapolis, MN, USA), and $100 \mathrm{ng} / \mathrm{ml}$ soluble receptor activator of $\mathrm{NF}-\kappa \mathrm{B}$ ligand (RANKL; supplied by Snow Brand Milk Products, Tokyo, Japan). The medium was changed on the fourth day in culture. On the nineth day in culture, the cells were fixed with 4\% paraformaldehyde in PBS ( $\mathrm{pH} \mathrm{7.4)} \mathrm{for} 5 \mathrm{~min}$ and fixed in ethyl alcohol with acetone for $1 \mathrm{~min}$ and dried in air. The samples were treated with $5 \mathrm{mg}$ naphthol AS-MX

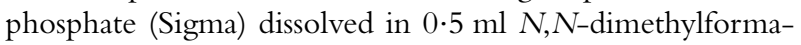
mide (WAKO) containing $50 \mathrm{mM}$ sodium tartrate (WAKO) and $30 \mathrm{mg}$ fast red violet LB salt (Sigma) in $50 \mathrm{ml} 0.1 \mathrm{M}$ sodium acetate buffer $(\mathrm{pH} 5 \cdot 0)$ for $10 \mathrm{~min}$ at room temperature. After rinsing the samples with water, the number of TRAP-positive multinucleated (cells containing more than two nuclei) osteoclast-like cells was counted under a light microscope. Quantitative analysis of the cell spreading was conducted according to the method described previously (Teti et al. 1998). After taking the micrographs of the cells, the cell maximal diameter (stretch) was measured by using a Luzex-F automated image analysis system (NIRECO). For each sample, over 80 osteoclast-like cells were evaluated.

\section{Statistical analysis}

The results were presented as mean values \pm s.E.M). Statistical analysis was performed by Mann-Whitney's $U$-test. A $P$ value of $<0 \cdot 05$ was considered to be statistically significant.

\section{Results}

$\mathrm{OPN}-1-$ mice showed resistance to bone loss induced by tail suspension

We previously reported that $\mathrm{OPN}-/-$ mice when they were subjected to tail suspension for 2 and 4 weeks showed resistance to unloading-induced reduction in $\mathrm{BV} / \mathrm{TV}$ (Ishijima et al. 2001). In this study, neither the increase in osteoclast number nor the suppression of osteoblastic activities was observed in $\mathrm{OPN}-/-$ mice subjected to unloading. Although OPN is known to be involved in bone resorption (Yoshitake et al. 1999), OPN deficiency-induced reduction in suppression of bone formation caused by unloading cannot be explained by the role of OPN in bone resorption because bisphosphonate did not block unloadinginduced reduction in bone formation (Kodama et al. 1997). Therefore, these data clearly indicate that OPN has a crucial role in the process of signal transduction pathways of mechanical stress in bone. However, one possibility remained obscure that bone loss induced by the absence of mechanical stress by tail suspension could be recovered after 2 and/or 4 weeks of tail suspension in $\mathrm{OPN}-/-$ mice, since unloading-induced reduction of bone formation rate was not recognized in OPN $-/-$ mice (Ishijima et al. 2001). Therefore, in this study, OPN $-/-$ and wild-type mice were subjected to tail suspension for 1 week to clarify this possibility. As presented in Fig. 1, in wild-type mice, $\mathrm{BV} / \mathrm{TV}$ in the secondary spongiosa of the tibia after 7 days of tail suspension was significantly reduced compared with

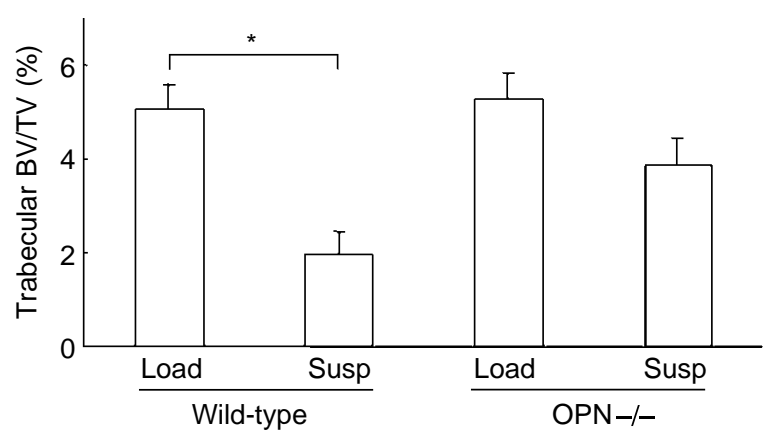

Figure 1 Trabecular bone volume of the tibiae of loaded and unloaded mice. Fractional trabecular bone volume (BV/TV) was quantified based on the image of microcomputed tomography $(\mu \mathrm{CT})$ pictures of the tibiae after 1 week of either tail suspension (Susp) or loading (Load) in wild-type (wild-type) or OPN - / - mice $(\mathrm{OPN}-/-)$. Data are expressed as means and standard errors for wild-type and OPN $-/-$ mice. ${ }^{*} P<0 \cdot 05$ 
that in loaded control. In contrast, this reduction of $\mathrm{BV} / \mathrm{TV}$ was not observed in OPN $-/-$ mice even after 7 days of tail suspension (Fig. 1). These data denied the possibility that $\mathrm{OPN}-/-$ mice showed early recovery from unloadinginduced bone loss as mentioned above. Therefore, these results, combined with our previous studies (Ishijima et al. 2001, 2002), clearly indicate that OPN is necessary for unloading-induced bone loss in vivo.

Formation of mineralized nodules of bone marrow cells obtained from femora subjected to unloading was reduced compared with that in of cells from loaded control, and OPN is required for this process

To examine the cellular activities underlying the phenomenon in $\mathrm{OPN}-/-$ mice, we next evaluated the characteristics of bone marrow cells after tail suspension. The numbers of bone marrow cells in the unloaded right femora were not altered compared with loaded control in either genotype after 7 days of tail suspension (Fig. 2).

In our previous report, while bone formation rate and mineral apposition rate were significantly reduced after tail suspension in wild-type mice, such reduction was not recognized in OPN $-/-$ mice (Ishijima et al. 2001, 2002). In this study, we first examined the cells involved in bone formation by estimating the efficiency in mineralized nodule formation. We used bone marrow cells prepared from mice after unloading in both genotypes. Mineralized nodules were observed in the bone marrow cells from both loaded and tailsuspended wild-type and OPN - / - animals cultured in the presence of ascorbic acid and $\beta$-glycerophosphate in the cells (Fig. 3A). However, the formation of mineralized nodules in the cells obtained from tail-suspended wild-type animals was less compared with the cells obtained from loaded wild-type animals (Fig. 3A, wild-type Load versus Susp). On the other

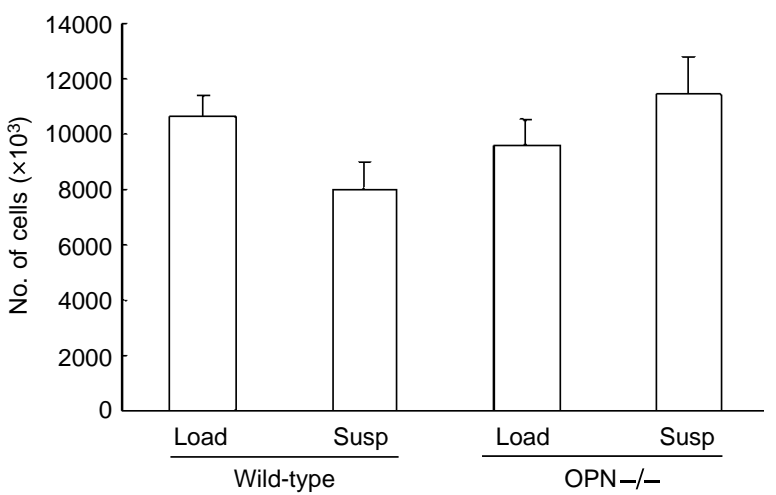

Figure 2 Number of bone marrow cells of loaded and unloaded mice. Bone marrow cells were obtained from the right femora after tail suspension (Susp) or loading (Load) in wild-type mice (wildtype) or OPN $-/-$ mice (OPN $-/-$ ). The number of the cells was counted as described in Materials and Methods. Data are expressed as means and standard errors for wild-type and OPN $-/-$ mice. hand, in OPN $-/-$ mice, this reduction in the formation of mineralized nodules in the cells obtained from tail suspended animals was not observed compared with the cells obtained from loaded animals (Fig. 3A, OPN - / - Load versus Susp).

Quantitative analysis of the mineralized nodule formation showed that in vitro formation of mineralized nodules in the cells obtained from the femora in loaded OPN $-/-$ mice was similar compared with that of the cells from loaded wildtype mice (Fig. 3B, OPN - / - Load versus wild-type Load). Formation of mineralized nodules in the cells from tailsuspended wild-type mice was significantly reduced compared with that of the cells from loaded wild-type mice (Fig. 3B, 84\% reduction, $P<0 \cdot 05$ ). In contrast, in the cells obtained from $\mathrm{OPN}-/-$ mice, the reduction of formation of mineralized nodules in cells obtained from tail suspended mice was not recognized when it was compared with that of the cells obtained from loaded mice (Fig. 3B, 21\% reduction, $P=0 \cdot 28)$. These results showed that unloading decreased the ability to form mineralized nodules in bone marrow cells and OPN has a crucial role in transmitting the signals of mechanical stress to the bone marrow cells.

Unloading enhances spreading of osteoclast-like cells and this enhancement of spreading of osteoclast-like cells was impaired due to the absence of OPN in vitro

We next examined the cells involved in bone resorption by in vitro osteoclastogenesis induced by the treatment with RANKL and M-CSF in the bone marrow cells. We utilized these two cytokines, RANKL and M-CSF, as described elsewhere (Ross \& Teitelbaum 2005). The numbers of TRAP-positive multinucleated osteoclast-like cells developed in the cultures of bone marrow cells obtained from loaded $\mathrm{OPN}-/$ - mice were similar to those in loaded wild-type mice (Table 1). Unloading of both OPN - / - and wild-type mice did not affect the numbers of osteoclast-like cells developed in the bone marrow cells obtained from these mice (Table 1).

However, as shown in the pictures in Fig. 4A, unloading enhanced spreading of osteoclast-like cells in bone marrow cell cultures compared with that of bone marrow cell cultures obtained from loaded wild-type mice. Quantitative analyses according to the method described previously (Teti et al. 1998) indicated that the maximal diameters of the osteoclastlike cells developed in the marrow cells from tail suspended wild-type mice were significantly greater than those from loaded mice in wild-type (Fig. 4B, 66.6\% increase, $P<0 \cdot 05$ ).

Spreading of the TRAP-positive cells derived from bone marrow cells obtained from loaded $\mathrm{OPN}-/-$ mice was similar in comparison with that of the loaded wild-type mice (Fig. 4A). However, as shown in the pictures in Fig. 4A, spreading of the TRAP-positive cells derived from bone marrow cells obtained from unloaded OPN $-/-$ mice was similar compared with that of cells from loaded OPN - / mice. Quantification of the spreading by measuring maximal diameters of the TRAP-positive multinucleated cells indicated that unloading-induced enhancement of spreading of 
A

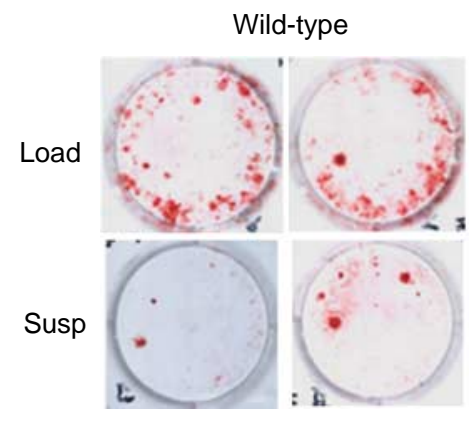

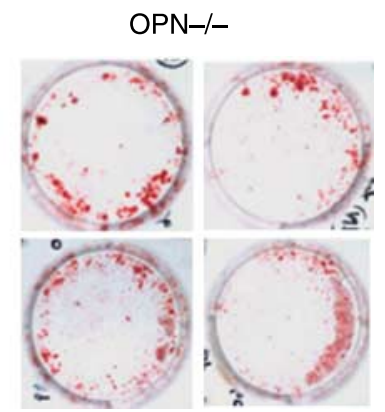

B

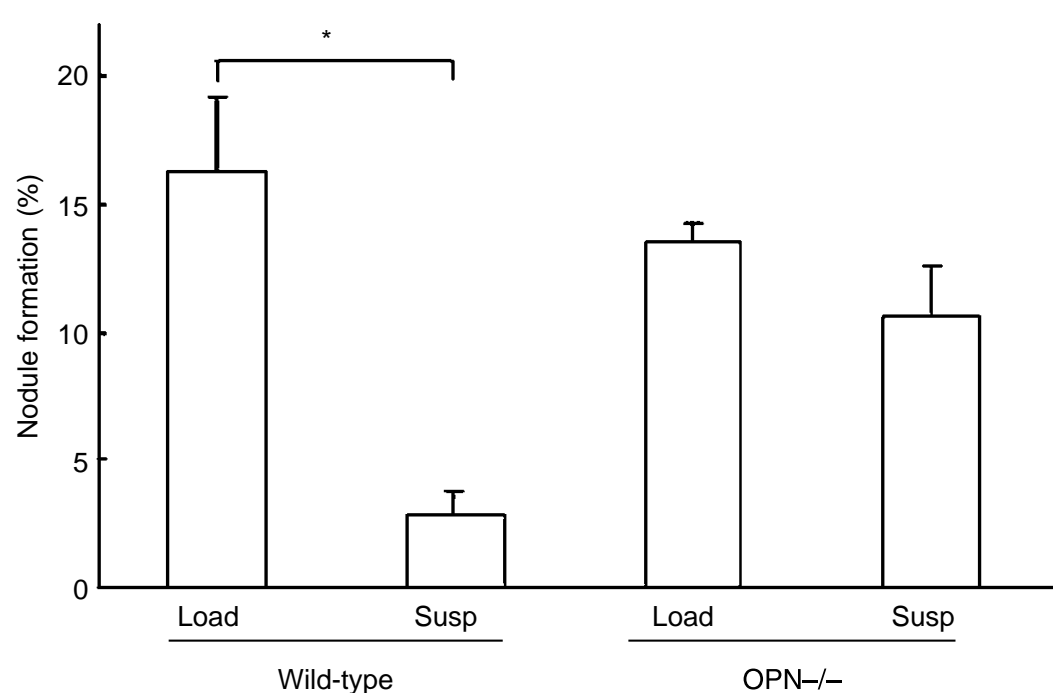

Figure 3 Mineralized nodule formation in the cultures of bone marrow cells obtained from loaded and unloaded mice. (A) Bone marrow cells from right femora after tail suspension (Susp) or loading (Load) in wild-type mice (wild-type) or OPN - / - mice (OPN $-/-$ ) were cultured in the presence of $50 \mu \mathrm{g} / \mathrm{ml}$ ascorbic acid and $10 \mathrm{mM}$ $\beta$-glycerophosphate. On the 21 st day in culture, the cells were stained with a solution of Alizarin Red as described in Materials and Methods. Two representative samples of each group are presented. (B) Quantification of the number of mineralized nodules formed in the cultures of bone marrow cells obtained from loaded and unloaded (Susp) mice. The percentage of surface area covered with mineralized nodules was measured as described in Materials and Methods. Data are expressed as means and standard errors for wild-type and OPN $-/-$ mice. Asterisk $\left(^{*}\right)$ indicates statistically significant difference from respective control $(P<0 \cdot 05)$.

these cells was not recognized in the bone marrow cells obtained from OPN-deficient mice (Fig. 4B, OPN $-/-$ Susp versus OPN $-/-$ Load).

\section{Discussion}

This study showed that OPN is a prerequisite for bone loss induced by the absence of mechanical stress and, moreover, affects osteoblastic and osteoclastic differentiation of bone marrow cells when they are subjected to loss of mechanical stress.
Osteocytes and osteoblasts are thought to regulate bone structure and bone mass by responding to mechanical stress (Burger \& Klein-Nulend 1999). In addition to these cells, bone marrow cells may also be regulated by mechanical stress as well as growth factors, cytokines, and hormones (Sakai et al. 1998, 2002, Sakata et al. 1999). As osteoblasts and osteoclasts differentiate from mesenchymal and hematopoietic stem cells respectively, the changes of local bone turnover are well associated with osteoblastic and osteoclastic differentiation of bone marrow cells. Thus, we observed the characteristics of bone marrow cells in the femora in $\mathrm{OPN}-/-$ mice after tail suspension to elucidate the role of OPN in osteoblastic and osteoclastic differentiation of bone marrow cells regulated by 
Table 1 Quantification of the number of tartrate-resistant acid phosphatase (TRAP)-positive osteoclast-like cells formed in the cultures of bone marrow cells obtained from loaded or unloaded mice. Data are expressed as means and standard errors for wild-type and OPN $-/-$ mice

\section{Tail suspension}

Genotype

Wild-type

Wild-type

OPN $-1-$

$\mathrm{OPN}-1-$
Number of osteoclast-like cells (per well)

$398 \cdot 0+161 \cdot 9$

$408 \cdot 3 \pm 226 \cdot 7$

$417 \cdot 0 \pm 199 \cdot 6$

$401 \cdot 3 \pm 197 \cdot 1$
Bone marrow cells obtained from tail suspended (susp) or loaded (load) wildtype mice (wild-type) or OPN $-/-$ mice (OPN $-/-$ ) were cultured in the presence of M-CSF and RANKL. The TRAP-positive multinucleated osteoclastlike cells were counted as described in Materials and Methods.

mechanical stress. It is known that unloading decreases bone formation in unloaded bones and cultured osteoprogenitor cells retain a memory of their prior loading history (Kostenuik et al. 1997). In our previous study, bone formation did not decrease in OPN $-/-$ mice when they were subjected to tail suspension, while it was reduced in wild-type mice (Ishijima et al. 2001). The results of in vitro mineralized nodule formation of bone marrow cells from unloaded bone in this study could be one of the mechanisms of resistance to unloading-induced suppression of bone formation in $\mathrm{OPN}-/-$ mice in our in vivo previous study described above. Therefore, lack of reduction in bone formation by the loss of mechanical stress in the absent of OPN would be resulted in part in the loss of signals for differentiation of osteoblastic precursor cells in bone marrow cells.

Recent data revealed that unloading induces resistance to insulin-like growth factor-I (IGF-I) by inhibiting activation of the IGF-I signaling pathways through down-regulation of $\alpha_{v} \beta_{3}$ integrin in bone marrow cells (Sakata et al. 2004). IGFbinding protein-5 (IGFBP-5), which is one of the six forms of IGFBPs, binds to OPN, and these interactions are considered to modulate the cooperative actions between the IGF-I receptor and integrin receptor signaling pathways (Nam et al. 2000). Although the precise role of OPN in the loss of signals for differentiation of osteoblastic precursor cells in bone marrow cells in response to reduction in mechanical stress is unclear, one of the possibilities could be that OPN may be involved in these interactions between IGF-I, IGF receptor (IGF-R), IGFBP-5, and $\alpha_{v} \beta_{3}$ integrin in bone marrow cells. In addition, OPN may have a role in alterations of blood flow in hind limbs of unloaded animals, because OPN is reported to be involved in vasculogenesis (Asou et al. 2001, Yumoto et al. 2002, Pritzker et al. 2004, Cheriyath \& Hussein, 2005). Blood perfusion is reduced in the bones of the hind limbs of tail-suspended animals (Colleran et al. 2000). The loss of alkaline phosphatase activity after unloading is closely associated with the suppression of platelet endothelial cell adhesion molecule-1 (CD31) signaling on the bone marrow cell surface (Sakuma-Zenke et al. 2005). Although further study is necessary to elucidate this possibility, OPN may be involved in this process.

In our previous study, unloading-induced enhancement in osteoclastic bone resorption was not observed in OPN - / mice (Ishijima et al. 2001). Therefore, we have gone on to ask whether the failure of the increase in osteoclast number following unloading is intrinsic to osteoclastogenesis in the bone marrow cells in OPN $-/-$ mice. The efficiencies of the formation of TRAP-positive multinucleated cells in the cultures of bone marrow cells obtained from the femora of unloaded and loaded mice in the presence of soluble RANKL and M-CSF were similar regardless of unloading or loading in either wild-type or $\mathrm{OPN}-/-$ mice. These results suggest that unloading does not affect the proportions of bone marrow cells, which are able to differentiate into osteoclasts in vitro at least under these conditions. Thus, the mechanism underlying the failure in unloading-induced increase in the number of osteoclasts in $\mathrm{OPN}-/-$ mice is not intrinsic.

Previous study reported that the number of TRAP-positive osteoclast-like cells induced by bone marrow cells of the tibiae subjected to tail suspension was significantly increased compared with cells from loaded control (Sakata et al. 1999). These data are not consistent with our data in which the number of TRAP-positive osteoclast-like cells induced by bone marrow cells of the femora was similar regardless of unloading or loading in either wild-type or OPN $-/-$ mice (Table 1). However, for instance, while osteoclast-like cells were induced from bone marrow cells in the presence of soluble RANKL and M-CSF in our study, these were induced from bone marrow cells in the presence of human parathyroid hormone in the previous study (Sakata et al. 1999). Therefore, the differences in the results of osteoclastlike cell formation assay between the previous study by Sakata et al. and our study may be due to the differences in experimental procedures.

In this in vitro study, we found that spreading of TRAPpositive osteoclast-like cells induced by bone marrow cells of femora subjected to tail suspension was enhanced compared with cells of loaded femora in wild-type mice. Adherence of osteoclasts to the substrate and polarizing reorganization of their morphology are critical to the resorbing function (Teitelbaum 2000). Osteoclasts are target cells for several cytokines and growth factors, among which M-CSF is essential for both osteoclast development and function. Mature osteoclasts also contain the M-CSF receptor, $\mathrm{c}-\mathrm{fms}$, which is required for the survival, spreading, and migration of these cells. It has been revealed that M-CSF induces spreading of osteoclasts (Nakamura et al. 1998, Teti et al. 1998, Grey et al. 2000). This effect of M-CSF requires the integrity of the $\alpha_{v} \beta_{3}$ integrin and signals through the c-fms, non-receptor type tyrosine kinase, c-src, phosphatidylinositol 3-kinase, and phospholipase C $\gamma$ (Duong et al. 1998, Ducy et al. 2000, Nakamura et al. 2001, Sanjay et al. 2001). Although, no major histological alterations in osteoclasts in $\mathrm{OPN}-/-$ mice have been observed in our previous study in vivo (Rittling et al. 1998, Yoshitake et al. 1999, Ishijima et al. 2001), our present 
A

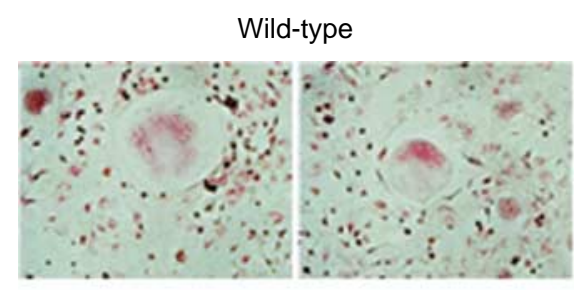

Load

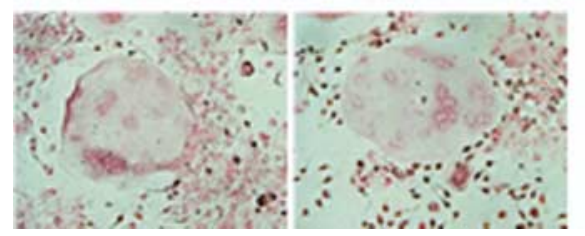

OPN-I-
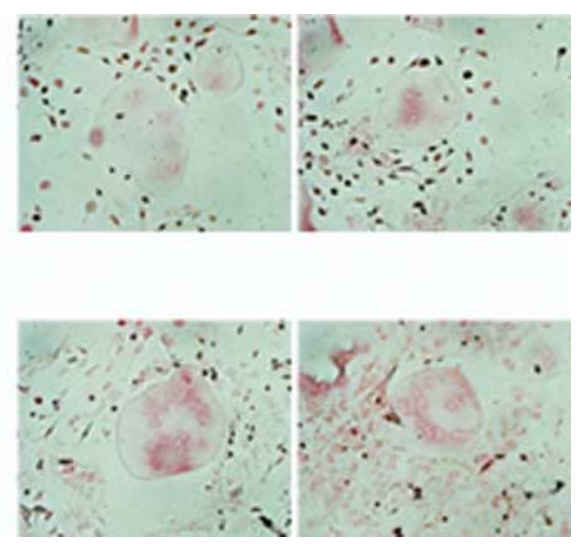

B

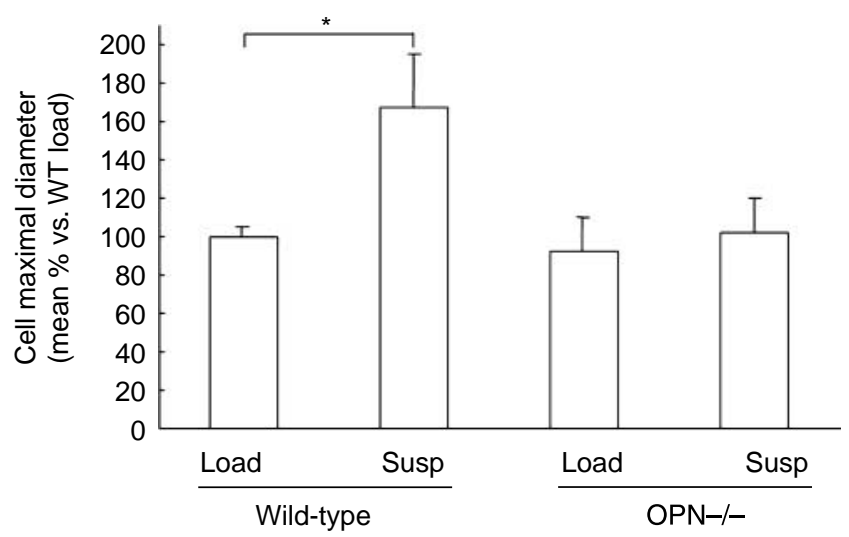

Figure 4 TRAP-positive osteoclast-like cell formation in the cultures of bone marrow cells obtained from loaded and unloaded mice. (A) Bone marrow cells from tail suspended (Susp) or loaded (Load) wild-type mice (wild-type) or OPN - / - mice (OPN - / - ) were cultured in the presence of $10 \mathrm{ng} / \mathrm{ml} \mathrm{M}$-CSF and $100 \mathrm{ng} / \mathrm{ml}$ RANKL. TRAP staining was conducted as described in Materials and Methods. Two representative independent plates out of six plates in each group are presented. (B) Spreading of TRAP-positive osteoclast like cells formed in the cultures of bone marrow cells obtained from tail suspended (Susp) or loaded (Load) wild-type mice (wild-type) or OPN $-/-$ mice (OPN - / - ). The maximal cell diameter was measured in at least 80 osteoclastlike cells as described in Materials and Methods. Data are expressed as relative values against loaded wild-type (WT) cells $(100 \%)$. Means and standard errors are indicated for wild-type and OPN $-/-$ mice. Asterisk $(*)$ indicates statistically significant difference from respective control $(P<0 \cdot 05)$.

in vitro data suggest that response of bone marrow cells to these cytokines may be increased due to unloading and OPN may be involved in this process. Our observations on the bone marrow cells obtained from mice after tail suspension are consistent with those of our previous data, in which unloading enhanced the excretion of deoxypyridinoline in urine as a systemic biochemical marker of bone resorption in wild-type mice and this enhancement of the excretion of deoxypyridinoline in urine was not recognized in OPN - / mice (Ishijima et al. 2001). Although which cells are involved and how they sense mechanical stress in bone is still unclear (Rodan, 1991), some reports have shown that osteoclasts respond to mechanical stress and, as a result, alter their boneresorbing activity (Rubin et al. 1999, Kurata et al. 2001). These results suggest that OPN has an important role in spreading of osteoclasts in response to mechanical stress, which may modulate the function of these cells.

In conclusion, these data suggest that OPN may be involved in the regulation not only of osteoclastic spreading but also of osteoblastic bone nodule formation in vitro regulated by the alterations of mechanical stress. Based on this and our previous studies (Ishijima et al. 2001, 2002), because further study is required to elucidate the precise role of OPN on signal transduction pathways of mechanical stress in bone, we are planning to conduct microarray analysis using mRNA extracted from bone marrow cells in hind limb bones of OPN $-/-$ mice subjected to unloading. Overall, our data support the notion that OPN plays a role in the signal transduction pathways of mechanical stress to bone marrow cells as well as osteoblasts and osteoclasts. 


\section{Acknowledgements}

This research was supported by the grants-in-aid received from the Ministry of Education (21st Century Center of Excellence (COE) Program, Frontier Research for Molecular Destruction and Reconstitution of Tooth and Bone, 18109011, 18659438, 18123456).

\section{Funding}

Grants have been received from Japan Space Forum, NASDA, and Japan Society for Promotion of Science (JSPS Core to Core Program on Advanced Bone and Joint Science (ABJS), Research for the Future Program, Genome Science). The authors declare that there is no conflict of interest that would prejudice the impartiality of this scientific work.

\section{References}

Asou Y, Rittling SR, Yoshitake H, Tsuji K, Shinomiya K, Nifuji A, Denhardt DT \& Noda M 2001 Osteopontin facilitates angiogenesis, accumulation of osteoclasts, and resorption in ectopic bone. Endocrinology 142 1325-1332.

Barou O, Palle S, Vico L, Alexandre C \& Lafage-Proust MH 1998 Hindlimb unloading in rat decreases preosteoblast proliferation assessed in vivo with BrdU incorporation. American Journal of Physiology 274 E108-E114.

Bikle DD \& Halloran BP 1999 The response of bone to unloading. Journal of Bone and Mineral Metabolism 17 233-244.

Bikle DD, Halloran BP, Cone CM \& Morey-Holton E 1985 Bone loss during simulated weightlessness: is it glucocorticoid mediated? Physiologist $\mathbf{2 8}$ S123-S124.

Bikle DD, Harris J, Halloran BP \& Morey-Holton ER 1994 Skeletal unloading induces resistance to insulin-like growth factor I. Journal of Bone and Mineral Research 9 1789-1796.

Burger EH \& Klein-Nulend J 1999 Mechanotransduction in bone-role of the lacuno-canalicular network. FASEB Journal 13 S101-S112.

Butler WT, Ridall AL \& McKee MD 1996 Osteopontin. In Principles of Bone Biology, pp 167-181. Eds JP Bilezikian, LG Raisz \& GA Rodan. San Diego: Academic Press, Inc.

Carvalho RS, Schaffer JL \& Gerstenfeld LC 1998 Osteoblasts induce osteopontin expression in response to attachment on fibronectin: demonstration of a common role for integrin receptors in the signal transduction processes of cell attachment and mechanical stimulation. Journal of Cellular Biochemistry 70 376-390.

Cheriyath V \& Hussein MA 2005 Osteopontin, angiogenesis and multiple myeloma. Leukemia 19 2203-2205.

Colleran PN, Wilkerson MK, Bloomfield SA, Suva LJ, Turner RT \& Delp MD 2000 Alterations in skeletal perfusion with simulated microgravity: a possible mechanism for bone remodeling. Journal of Applied Physiology $\mathbf{8 9}$ 1046-1054.

Denhardt DT \& Noda M 1998 Osteopontin expression and function: role in bone remodeling. Journal of Cellular Biochemistry. Supplement 30-31 92-102.

Denhardt DT, Noda M, O'Regan AW, Pavlin D \& Berman JS 2001a Osteopontin as a means to cope with environmental insults: regulation of inflammation, tissue remodeling, and cell survival. Journal of Clinical Investigation 107 1055-1061.

Denhardt DT, Burger EH, Kazanecki C, Krishna S, Semeins CM \& KleinNulend J 2001b Osteopontin-deficient bone cells are defective in their ability to produce NO in response to pulsatile fluid flow. Biochemical and Biophysical Research Communications 288 448-453.

Ducy P, Schinke T \& Karsenty G 2000 The osteoblast: a sophisticated fibroblast under central surveillance. Science 289 1501-1504.
Duong LT, Lakkakorpi PT, Nakamura I, Machwate M, Nagy RM \& Rodan GA 1998 PYK2 in osteoclasts is an adhesion kinase, localized in the sealing zone, activated by ligation of alpha(v)beta 3 integrin, and phosphorylated by src kinase. Journal of Clinical Investigation 102 881-892.

Giachelli CM \& Steitz S 2000 Osteopontin: a versatile regulator of inflammation and biomineralization. Matrix Biology 19 615-622.

Grey A, Chen Y, Paliwal I, Carlberg K \& Insogna K 2000 Evidence for a functional association between phosphatidylinositol 3-kinase and c-src in the spreading response of osteoclasts to colony-stimulating factor-1. Endocrinology 141 2129-2138.

Harter LV, Hruska KA \& Duncan RL 1995 Human osteoblast-like cells respond to mechanical strain with increased bone matrix protein production independent of hormonal regulation. Endocrinology $136528-535$.

Ihara H, Denhardt DT, Furuya K, Yamashita T, Muguruma Y, Tsuji K, Hruska KA, Higashio K, Enomoto S, Nifuji A et al. 2001 Parathyroid hormoneinduced bone resorption does not occur in the absence of osteopontin. Journal of Biological Chemistry 276 13065-13071.

Ingber D 1999 How cells (might) sense microgravity. FASEB Journal 13 S3-S15. Ishijima M, Rittling SR, Yamashita T, Tsuji K, Kurosawa H, Nifuji A, Denhardt DT \& Noda M 2001 Enhancement of osteoclastic bone resorption and suppression of osteoblastic bone formation in response to reduced mechanical stress do not occur in the absence of osteopontin. Journal of Experimental Medicine 193 399-404.

Ishijima M, Tsuji K, Rittling SR, Yamashita T, Kurosawa H, Denhardt DT, Nifuji A \& Noda M 2002 Resistance to unloading-induced threedimensional bone loss in osteopontin-deficient mice. Journal of Bone and Mineral Research 17 661-667.

Keila S, Pitaru S, Grosskopf A \& Weinreb M 1994 Bone marrow from mechanically unloaded rat bones expresses reduced osteogenic capacity in vitro. Journal of Bone and Mineral Research 9 321-327.

Kitahara K, Ishijima M, Rittling SR, Tsuji K, Kurosawa H, Nifuji A, Denhardt DT \& Noda M 2003 Osteopontin deficiency induces parathyroid hormone enhancement of cortical bone formation. Endocrinology 144 2132-2140.

Klein-Nulend J, Roelofsen J, Semeins CM, Bronckers AL \& Burger EH 1997 Mechanical stimulation of osteopontin mRNA expression and synthesis in bone cell cultures. Journal of Cellular Physiology 170 174-181.

Kodama Y, Nakayama K, Fuse H, Fukumoto S, Kawahara H, Takahashi H, Kurokawa T, Sekiguchi C, Nakamura T \& Matsumoto T 1997 Inhibition of bone resorption by pamidronate cannot restore normal gain in cortical bone mass and strength in tail-suspended rapidly growing rats. Journal of Bone and Mineral Research 12 1058-1067.

Koike M, Shimokawa H, Kanno Z, Ohya K \& Soma K 2005 Effects of mechanical strain on proliferation and differentiation of bone marrow stromal cell line ST2. Journal of Bone and Mineral Metabolism 23 219-225.

Kostenuik PJ, Halloran BP, Morey-Holton ER \& Bikle DD 1997 Skeletal unloading inhibits the in vitro proliferation and differentiation of rat osteoprogenitor cells. American Journal of Physiology 273 E1133-E1139.

Kostenuik PJ, Harris J, Halloran BP, Turner RT, Morey-Holton ER \& Bikle DD 1999 Skeletal unloading causes resistance of osteoprogenitor cells to parathyroid hormone and to insulin-like growth factor-I. Journal of Bone and Mineral Research 14 21-31.

Kubota T, Yamauchi M, Onozaki J, Sato S, Suzuki Y \& Sodek J 1993 Influence of an intermittent compressive force on matrix protein expression by ROS $17 / 2.8$ cells, with selective stimulation of osteopontin. Archives of Oral Biology 38 23-30.

Kurata K, Uemura T, Nemoto A, Tateishi T, Murakami T, Higaki H, Miura H \& Iwamoto Y 2001 Mechanical strain effect on bone-resorbing activity and messenger RNA expressions of marker enzymes in isolated osteoclast culture. Journal of Bone and Mineral Research 16 722-730.

Lian JB, Stein GS, Canalis E, Robey PG \& Boskey AL 1996 Bone formation: osteoblast lineage cells, growth factors, matrix proteins, and the mineralization process. In Principles of Bone Biology, pp 14-29. Eds JP Bilezikian, LG Raisz \& GA Rodan. San Diego: Academic Press, Inc.

Manolagas SC 2000 Birth and death of bone cells: basic regulatory mechanisms and implications for the pathogenesis and treatment of osteoporosis. Endocrine Reviews 21 115-137. 
Mauney JR, Sjostorm S, Blumberg J, Horan R, O’Leary JP, VunjakNovakovic G, Volloch V \& Kaplan DL 2004 Mechanical stimulation promotes osteogenic differentiation of human bone marrow stromal cells on 3-D partially demineralized bone scaffolds in vitro. Calcified Tissue International 74 458-468.

Meazzini MC, Toma CD, Schaffer JL, Gray ML \& Gerstenfeld LC 1998 Osteoblast cytoskeletal modulation in response to mechanical strain in vitro. Journal of Orthopaedic Research 16 170-180.

Miles RR, Turner CH, Santerre R, Tu Y, McClelland P, Argot J, DeHoff BS, Mundy CW, Rosteck PR Jr, Bidwell J et al. 1998 Analysis of differential gene expression in rat tibia after an osteogenic stimulus in vivo: mechanical loading regulates osteopontin and myeloperoxidase. Journal of Cellular Biochemistry 68 355-365.

Morey ER \& Baylink DJ 1978 Inhibition of bone formation during space flight. Science 201 1138-1141.

Morinobu M, Ishijima M, Rittling SR, Tsuji K, Yamamoto H, Nifuji A, Denhardt DT \& Noda M 2003 Osteopontin expression in osteoblasts and osteocytes during bone formation under mechanical stress in the calvarial suture in vivo. Journal of Bone and Mineral Research 18 1706-1715.

Nakamura I, Jimi E, Duong LT, Sasaki T, Takahashi N, Rodan GA \& Suda T 1998 Tyrosine phosphorylation of p130Cas is involved in actin organization in osteoclasts. Journal of Biological Chemistry 273 11144-11149.

Nakamura I, Lipfert L, Rodan GA \& Le TD 2001 Convergence of alpha(v)beta(3) integrin- and macrophage colony stimulating factormediated signals on phospholipase Cgamma in prefusion osteoclasts. Journal of Cell Biology 152 361-374.

Nam TJ, Busby WH Jr, Rees C \& Clemmons DR 2000 Thrombospondin and osteopontin bind to insulin-like growth factor (IGF)-binding protein-5 leading to an alteration in IGF-I-stimulated cell growth. Endocrinology $\mathbf{1 4 1}$ 1100-1106.

Nemoto H, Rittling SR, Yoshitake H, Furuya K, Amagasa T, Tsuji K, Nifuji A, Denhardt DT \& Noda M 2001 Osteopontin deficiency reduces experimental tumor cell metastasis to bone and soft tissues. Journal of Bone and Mineral Research 16 652-659.

Nomura S \& Takano-Yamamoto T 2000 Molecular events caused by mechanical stress in bone. Matrix Biology 19 91-96.

Pritzker LB, Scatena M \& Giachelli CM 2004 The role of osteoprotegerin and tumor necrosis factor-related apoptosis-inducing ligand in human microvascular endothelial cell survival. Molecular Biology of the Cell 15 2834-2841.

Rittling SR \& Denhardt DT 1999 Osteopontin function in pathology: lessons from osteopontin-deficient mice. Experimental Nephrology 7 103-113.

Rittling SR, Matsumoto HN, McKee MD, Nanci A, An XR, Novick KE, Kowalski AJ, Noda M \& Denhardt DT 1998 Mice lacking osteopontin show normal development and bone structure but display altered osteoclast formation in vitro. Journal of Bone and Mineral Research 13 1101-1111.

Rodan GA 1991 Mechanical loading, estrogen deficiency, and the coupling of bone formation to bone resorption. Journal of Bone and Mineral Research 6 527-530.

Ross FP \& Teitelbaum SL 2005 Alphavbeta3 and macrophage colonystimulating factor: partners in osteoclast biology. Immunological Reviews $\mathbf{2 0 8}$ 88-105.

Rubin J, Fan X, Biskobing DM, Taylor WR \& Rubin CT 1999 Osteoclastogenesis is repressed by mechanical strain in an in vitro model. Journal of Orthopaedic Research 17 639-645.

Rubin C, Xu G \& Judex S 2001a The anabolic activity of bone tissue, suppressed by disuse, is normalized by brief exposure to extremely lowmagnitude mechanical stimuli. FASEB Journal 15 2225-2229.

Rubin C, Turner AS, Bain S, Mallinckrodt C \& McLeod K $2001 b$ Anabolism. Low mechanical signals strengthen long bones. Nature 412 603-604.

Sakai A, Nishida S, Okimoto N, Okazaki Y, Hirano T, Norimura T, Suda T \& Nakamura T 1998 Bone marrow cell development and trabecular bone dynamics after ovariectomy in ddy mice. Bone 23 443-451.
Sakai A, Sakata T, Tanaka S, Okazaki R, Kunugita N, Norimura T \& Nakamura T 2002 Disruption of the $p 53$ gene results in preserved trabecular bone mass and bone formation after mechanical unloading. Journal of Bone and Mineral Research 17 119-127.

Sakata T, Sakai A, Tsurukami H, Okimoto N, Okazaki Y, Ikeda S, Norimura T \& Nakamura T 1999 Trabecular bone turnover and bone marrow cell development in tail- suspended mice. Journal of Bone and Mineral Research $\mathbf{1 4}$ 1596-1604.

Sakata T, Wang Y, Halloran BP, Elalieh HZ, Cao J \& Bikle DD 2004 Skeletal unloading induces resistance to insulin-like growth factor-I (IGF-I) by inhibiting activation of the IGF-I signaling pathways. Journal of Bone and Mineral Research 19 436-446.

Sakuma-Zenke M, Sakai A, Nakayamada S, Kunugita N, Tabata T, Uchida S, Tanaka S, Mori T, Nakai K, Tanaka Y et al. 2005 Reduced expression of platelet endothelial cell adhesion molecule-1 in bone marrow cells in mice after skeletal unloading. Journal of Bone and Mineral Research 20 1002-1010.

Sanjay A, Houghton A, Neff L, DiDomenico E, Bardelay C, Antoine E, Levy J, Gailit J, Bowtell D, Horne WC et al. 2001 Cbl associates with Pyk2 and Src to regulate Src kinase activity, alpha(v)beta(3) integrin-mediated signaling, cell adhesion, and osteoclast motility. Journal of Cell Biology 152 181-195.

Shyy JY \& Chien S 1997 Role of integrins in cellular responses to mechanical stress and adhesion. Current Opinion in Cell Biology 9 707-713.

Teitelbaum SL 2000 Bone resorption by osteoclasts. Science 289 1504-1508.

Terai K, Takano-Yamamoto T, Ohba Y, Hiura K, Sugimoto M, Sato M, Kawahata H, Inaguma N, Kitamura Y \& Nomura S 1999 Role of osteopontin in bone remodeling caused by mechanical stress. Journal of Bone and Mineral Research 14 839-849.

Teti A, Taranta A, Migliaccio S, Degiorgi A, Santandrea E, Villanova I, Faraggiana T, Chellaiah M \& Hruska KA 1998 Colony stimulating factor1-induced osteoclast spreading depends on substrate and requires the vitronectin receptor and the c-src proto-oncogene. Journal of Bone and Mineral Research 13 50-58.

Toma CD, Ashkar S, Gray ML, Schaffer JL \& Gerstenfeld LC 1997 Signal transduction of mechanical stimuli is dependent on microfilament integrity: identification of osteopontin as a mechanically induced gene in osteoblasts. Journal of Bone and Mineral Research 12 1626-1636.

Wang N, Butler JP \& Ingber DE 1993 Mechanotransduction across the cell surface and through the cytoskeleton. Science 260 1124-1127.

Wozniak M, Fausto A, Carron CP, Meyer DM \& Hruska KA 2000 Mechanically strained cells of the osteoblast lineage organize their extracellular matrix through unique sites of alphavbeta3-integrin expression. Journal of Bone and Mineral Research 15 1731-1745.

Yoshitake H, Rittling SR, Denhardt DT \& Noda M 1999 Osteopontindeficient mice are resistant to ovariectomy-induced bone resorption. PNAS 96 8156-8160.

You J, Reilly GC, Zhen X, Yellowley CE, Chen Q, Donahue HJ \& Jacobs CR 2001 Osteopontin gene regulation by oscillatory fluid flow via intracellular calcium mobilization and activation of mitogen-activated protein kinase in MC3T3-E1 osteoblasts. Journal of Biological Chemistry 276 13365-13371.

Yumoto K, Ishijima M, Rittling SR, Tsuji K, Tsuchiya Y, Kon S, Nifuji A, Uede T, Denhardt DT \& Noda M 2002 Osteopontin deficiency protects joints against destruction in anti-type II collagen antibody-induced arthritis in mice. PNAS 99 4556-4561.

Received in final form 8 September 2006

Accepted 26 September 2006

Made available online as an Accepted Preprint 29 January 2007 